\title{
Grey Correlation Degree-based Sports Activities and Old People Happi- ness Index Relationship Optimization Model Research
}

\author{
Guohua Shao*
}

Institute of Physical Education, Inner Mongolia Normal University, Hohhot 010022, Inner Mongolia, China

\begin{abstract}
Old people are one part of numerous groups in national life, and are also extremely important one group of people; by far old people problem has already been listed as priority in national security assurance work. And as one indicator that reflects old people life quality, happiness index tends to become the key whether a country is qualified in old people security aspect or not. The paper utilizes comprehensive analysis and comparative analysis method, targeted at Chinese old people physical exercises basic information and old people physical health status, it makes research, and points out that Chinese old people physical exercises age group in 55 75years old are in the majority, averagely daily exercise time basically are above 3 hours, their common diseases concurrency rate is lower with respect to before exercising. In addition, apply mathematics grey correlation degree method and goal programming method, establish sports activitiesbased old people happiness index optimization model, make quantitative analysis of square dance, Taijiquan, martial arts, badminton, sports dance are several kinds of sports activities of higher old people satisfaction index, from which Taijiquan, square dance, martial arts have largest impacts on old people happiness index.
\end{abstract}

Keywords: Goal programming, grey correlation degree, old people happiness index, physiological indicator, sports activities.

\section{INTRODUCTION}

Old people are one of Chinese vulnerable groups, their life standards, security assurance are important problems of national people concerns. With economic gradually development, medical levels gradually promotion, all kinds of age-related diseases curative levels also promote by quite a big level, old people happiness index are getting higher and higher. As one of Chinese people life influence factors, physical exercises also make certain contributions to old people happiness index promotion.

Chen Ai-Guo in the article "Physical exercise and old people happiness relations", took old people happiness as main starting orientation, by researching physical exercise and old people happiness index relations, analyzed its impacts on old people life happiness. The paper references formers research information, summarized and sorted relevant data, and made quantitative analysis of them, finally got conclusions. The paper pointed out : physical exercise not only had important impacts on promoting old people physical quality, physical and psychological health, but also could relieve and had certain curative effects on old people all kinds of diseases [1].

Dai Qun and Yao Jia-Xin etc. in the article "Physical exercise and old people life satisfaction index relationship: self-efficacy, social supports, self-esteem intermediation", from the perspective of old people physical exercise, researched on old people self-efficacy and other aspects, and then analyzed old people life satisfaction index suffered physical exercise impacts size [2].

The paper pointed out old people that regular engaged in physical exercise more contacted with society, their selfefficacy, ability of fusing into society were good, and self esteem sense was stronger. In life quality aspect, such part of old people was also obviously higher than old people group that less engaged in physical exercises [3].

Li Jin-Ping in the article " Influence of Participating in physical exercise on old people mental health, well-being rating and life quality as well as relative influence factors research", took old people mental health, well-being rating and life level as main research perspectives, by comparing each indicator of participating in physical exercises and didn't regular participate in physical exercises, finally got conclusions: old people that regular participated in physical exercises mental disorder occurrence odds were smaller, their happiness index and life quality were obviously higher, which had close relations with old people physical exercises consciousness, community physical exercises venues construction, government management system, national old people security assurance work and other aspects factors [4].

The paper utilizes above methods, references lots of data information and formers achievements, makes analysis of physical exercises and old people happiness index relations, further researches on contemporary old people satisfaction index highest and meanwhile most beneficial happiness index promotion physical exercise items, so that provides theoretical basis for Chinese old people living security work and Chinese sports development among old people group. 
Table 1. Old people physical exercise basic information.

\begin{tabular}{|c|c|c|c|c|}
\hline Age Group & $\mathbf{5 0 \sim 6 0}$ & $\mathbf{6 0 \sim 7 0}$ & $\mathbf{7 0 \sim 8 0}$ & $>\mathbf{8 0}$ \\
\hline \hline Participants amount percentage $\%$ & $38.5 \%$ & $47.4 \%$ & $40.1 \%$ & $25.2 \%$ \\
\hline Average exercise time $/ \mathrm{h}$ & 3.2 & 3.5 & 2.8 & 1.7 \\
\hline
\end{tabular}

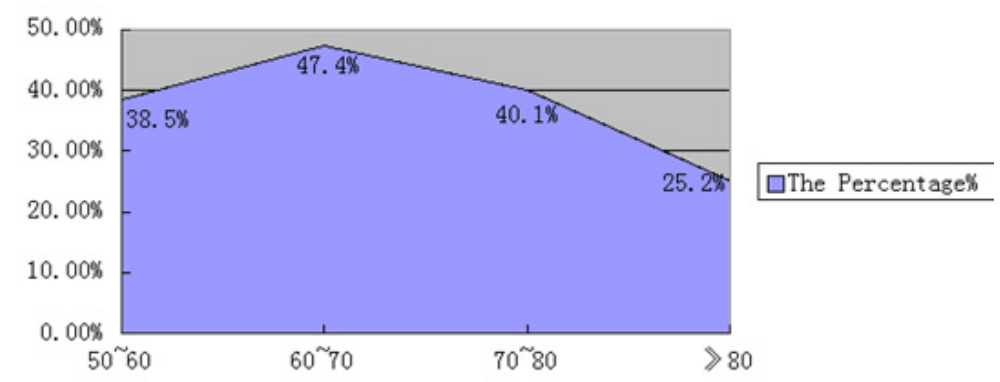

Fig. (1). The elderly physical exercise.

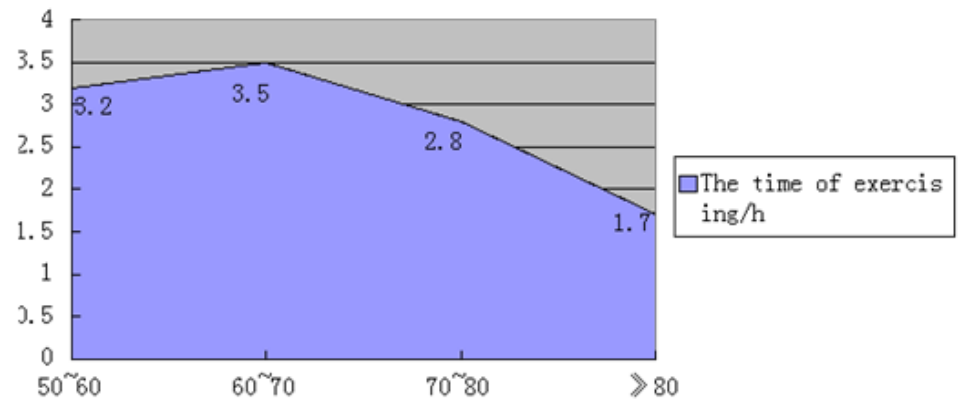

Fig. (2). The elderly physical exercise.

\section{CHINESE OLD PEOPLE PHYSICAL EXERCISE} BASIC INFORMATION

Affected by physical health factors, lots of old people cannot participate in physical exercises, and their participation physical exercises activities items are also very limited, square dance, Taijiquan, martial arts, sports dance, aerobics and swimming and so on are sports items that most of old people engagement, and similar to basketball, football and volleyball and other more intensity type ball exercises are not the main selection of old people exercises [5].

For old people favorite sports activities, apply correlation degree method and goal programming method to make comprehensive and quantitative analysis of them, and then study the kind of sports event and old people happiness index relations, and get old people happiness index maximum influential sports activities to provide theoretical references for sports development in the old people field [6].

For the old people group, their happiness index is an important criterion to evaluate whether a country do a good job in taking care of old people or not. As an important activity of promoting physical and psychological health, ease mind, and regulate emotion, physical exercise is one of most important paths to promote old people happiness index. According to investigation indication, presently all kinds of residential quarters establish old people physical exercise venues, basic physical exercise equipments are relative per- fect. In the aged apartment, nursing home and other venues, there are also setting specialized physical exercise fields, for different physiques old people, it sets different physical exercise facilities.

Table $\mathbf{1}$ is investigation on Chinese different age groups old people physical exercise participants amount and average exercise time, data is from general administration of sport of China data, internet correlation data.

Handle with above Table 1, and draw statistical Figs. (1 and 2).

From above statistical Fig. (1), it can analyze and get that when taking physical exercises, old people age concentrates on 50 80 years old, from which $60 \sim 70$ years old is in the majority. For old people physical exercise time, most of old people average exercise time is around 3 hours, old people of 50 60 years old select above 3 hours exercise time, and the elder ones, exercise time is basically below 3 hours, which is closely linked to their physical health status.

Senile dementia, hypertension, coronary heart disease, and depression are common diseases of the old people, and meanwhile they are also main factors that trouble old people physical health. For the curing of the diseases, chemical treatment's curative effects are also obviously different. In general, physical exercise is also one kind of effective way to cure disease, for Senile dementia, hypertension, coronary 
Table 2. Comparison of common old people diseases curative effects.

\begin{tabular}{|c|c|c|c|c|c|}
\hline & Senile Dementia & Hypertension & Coronary Heart Disease & Heart Disease & Depression \\
\hline \hline Physical exercise & $86.3 \%$ & $60.1 \%$ & $78.5 \%$ & $79.4 \%$ & $79.1 \%$ \\
\hline Chemical treatment & $74.5 \%$ & $61.2 \%$ & $78.2 \%$ & $83.2 \%$ & $62.5 \%$ \\
\hline
\end{tabular}

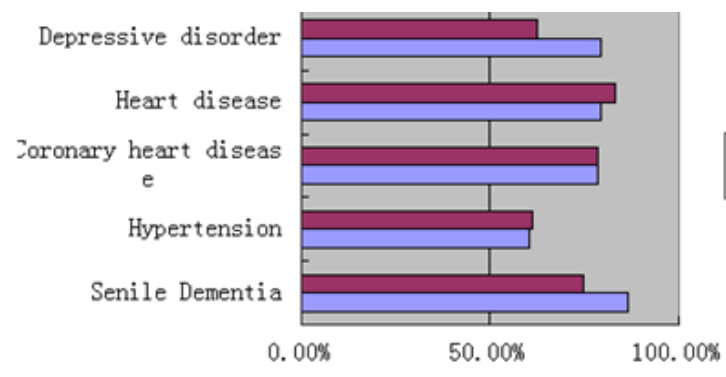

Fig. (3). The common to the old disease curative effect comparison.

heart disease, and depression these diseases, physical exercise also plays certain effects. Table 2 is comparison of curative effects on senile dementia, hypertension, coronary heart disease, and depression under physical exercises and medicine curing.

From above statistical Fig. (3), it can analyze and get: physical exercise curative effects on old people senile dementia and depression is obviously higher than chemical treatment, while chemical treatment curative effects on hypertension, coronary heart disease and heart diseases are better than physical exercises by comparing, but physical exercises also have certain curative effects.

\section{GREY CORRELATION DEGREE METHOD- BASED COMMON SPORTS ACTIVITIES AND OLD PEOPLE SATISFACTION INDEX RESEARCH}

The purpose of grey relational degree analysis is on the basis of system overall development change, if system change and factor change trend are consistent, then the two relational degree is larger; if system change and factor change trend are inconsistent, or exist certain differences, then the two relational degree are smaller.

\subsection{Data Processing}

Table 3 is old people regular engaged physical exercises items, their participants amount percentage, average participation time and satisfaction index numerical value table, data is from general administration of sport of China, China's statistical yearbook and internet correlation data. Make statistical analysis of following data.

\subsection{Establish Model}

(1) Record feature behaviors sequence as following:

$x_{i}^{\prime}=\left(x_{i}^{\prime}(1), x_{i}^{\prime}(2)\right)^{T}, i=1,2$, from which correlation factor line sequence is:

$$
x_{1}^{\prime}=(12.8,13 \cdot 1,12.7,10.4,10.2,9.6,5.2,3.1,17.9) \text {; }
$$

$$
x_{2}{ }^{\prime}=(3.5,4 \cdot 0,2 \cdot 1,3 \cdot 0,2 \cdot 5,2 \cdot 1,3 \cdot 2,3 \cdot 2,1.1)
$$

Thereupon, it can get:

$$
x_{i}^{\prime}=\left(\begin{array}{ccccccccc}
12.8 & 13.1 & 12.7 & 10.4 & 10.2 & 9.6 & 5.2 & 3.1 & 17.9 \\
3.5 & 4.0 & 2.1 & 3.0 & 2.5 & 2.1 & 3.2 & 3.3 & 1.1
\end{array}\right)
$$

Define reference sequence

Define satisfaction index sequence $x_{0}$ as reference sequence, that :

$$
x_{0}{ }^{\prime}=(12.6,13.2,10.2,11.9,11.3,7.0,11.2,5.3,2.7)
$$

Initialization method data processing

Utilize formula,

$$
x_{i}(k)=\frac{x_{i}^{\prime}(k)}{x_{i}^{\prime}(1)}
$$

to handle with relative factors line sequence, result is as following :

$$
\begin{aligned}
& x_{1}(k)=\frac{x_{1}^{\prime}(k)}{x_{1}^{\prime}(1)}=(1,1.02,1.14,0.69,0.99,0.80,0.81,0.58,0.41) \\
& x_{2}(k)=\frac{x_{2}^{\prime}(k)}{x_{2}^{\prime}(1)}=(1,0.88,1,0.88,0.88,0.82,0.76,0.71,0.71)
\end{aligned}
$$

Calculate

$\min _{1 \leq i \leq 3} \min _{1 \leq k \leq 3}\left|x_{0}{ }^{\prime}-x_{i}(k)\right|, \max _{1 \leq i \leq 3} \max _{1 \leq k \leq 3}\left|x_{0}{ }^{\prime}-x_{i}(k)\right|$

Input $x_{1}(k), x_{2}(k), x_{0}^{\prime}$ into above formula and get:

$$
\min _{1 \leq i \leq 3} \min _{1 \leq k \leq 3} \mid x_{0}^{\prime}-x_{i}(k)=28.46
$$

$\max _{1 \leq i \leq 3} \max _{1 \leq k \leq 3}\left|x_{0}{ }^{\prime}-x_{i}(k)\right|=29.55$

Calculate correlation coefficient 
Table 3. Data statistical table.

\begin{tabular}{|c|c|c|c|c|c|c|c|c|c|}
\hline Course content & Square dance & Taijiquan & Martial Arts & Badminton & Aerobics & Sports Dance & Shuttlecock & Swimming & Others \\
\hline Participants amount percentage $\%$ & 12.8 & 13.1 & 12.7 & 10.4 & 10.2 & 9.6 & 5.2 & 3.1 & 17.9 \\
\hline Average participation time $/ \mathrm{h}$ & 3.5 & 4.0 & 2.1 & 3.0 & 2.5 & 2.1 & 3.2 & 3.3 & 1.1 \\
\hline Satisfaction index $\%$ & 12.6 & 13.2 & 10.2 & 11.9 & 11.3 & 7.0 & 11.2 & 5.3 & 2.7 \\
\hline
\end{tabular}

Table 4. Correlation degree value.

\begin{tabular}{|c|c|c|c|c|c|c|c|c|c|}
\hline $\begin{array}{l}\text { Course } \\
\text { Content }\end{array}$ & $\begin{array}{l}\text { Square } \\
\text { Dance }\end{array}$ & Taijiquan & $\begin{array}{c}\text { Martial } \\
\text { Arts }\end{array}$ & Badminton & $\begin{array}{l}\text { Sports } \\
\text { Dance }\end{array}$ & Aerobics & Shuttlecock & Swimming & Others \\
\hline $\begin{array}{c}\text { Correlation } \\
\text { degree value }\end{array}$ & 1.081 & 1.082 & 1.079 & 1.054 & 1.09 & 0.775 & 0.857 & 0.654 & 0.862 \\
\hline
\end{tabular}

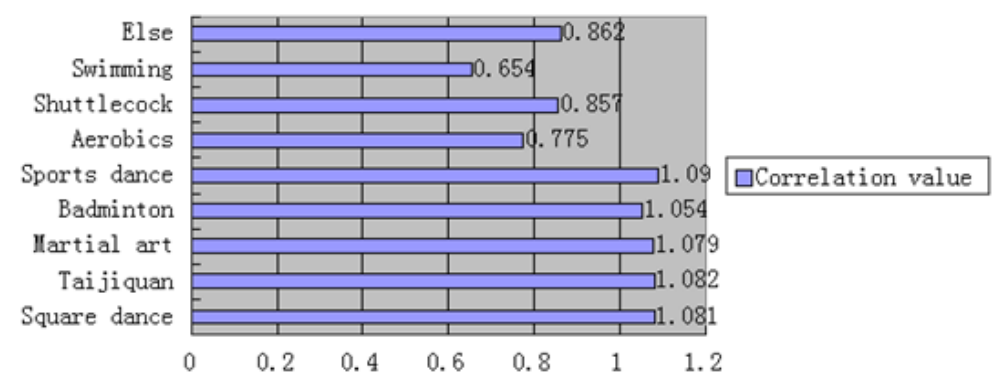

Fig. (4). The correlation value.

Below is correlation coefficient computational formula:

$$
\zeta_{i}(k)=\frac{\min _{1 \leq i \leq n} \min _{1 \leq k \leq m}\left|x_{0}^{\prime}(k)-x_{i}(k)\right|+\rho \times \max _{1 \leq i \leq n} \max _{1 \leq k \leq m}\left|x_{0}^{\prime}(k)-x_{i}(k)\right|}{\left|x_{0}^{\prime}(k)-x_{i}(k)\right|+\rho \times \max _{1 \leq i \leq n} \max _{1 \leq k \leq m}\left|x_{0}^{\prime}(k)-x_{i}(k)\right|}
$$

Among them, $\rho$ is resolution ratio, and $\rho \in(0,1)$, $\rho=0.5, \rho$ gets bigger and then relation is bigger.

Input $\left|x_{0}^{\prime}(k)-x_{i}(k)\right|$ each value, and can solve:

$\zeta_{1}=(1.14,1.01,0.989,0.978,0.924,0.991,1.02,0.997,0.875)$;

$\zeta_{2}=(1.14,1.11,0.996,0.987,0.893,0.975,1.201,1.012,1.114)$

Calculate correlation degree

Use correlation degree computational formula $r_{i}=\frac{1}{m} \sum_{k=1}^{m} \zeta_{i}(k)$, input above correlation coefficient and get :

$$
r_{1}=1.081, r_{2}=1.082, r_{3}=1.079, r_{4}=1.054, r_{5}=1.090 \text {, }
$$

$r_{6}=0.775, r_{7}=0.857$,

$r_{8}=0.654, r_{9}=0.862$

And then it gets following data Table 4:

(7) Evaluation result

Draw above result into statistical Fig. (4), and analyze conclusion:
From above correlation degree result, it is clear that for square dance, taijiquan, martial arts, badminton, sports dance, aerobics, swimming, shuttlecock and other sports activities, considering old people age, physical quality, exercise time, participants amount and other factors, finally it gets that square dance, taijiquan, martial arts, badminton, and sports dance are sports activities of higher old people satisfaction index, and also sports activities that old people regular engage in.

\section{GOAL PROGRAMMING METHOD-BASED SPORTS ACTIVITIES AND OLD PEOPLE HAPPI- NESS INDEX}

For common old people sports events, on the basis of carrying out grey correlation degree analysis of them, it is clear that square dance, taijiquan, martial arts, badminton, sports dance old people satisfaction index are the highest. Therefore, we base on this, carry out goal programming analysis, research these sports activities and old people happiness index connections, and then get in case carry out physical exercises, old people happiness index highest sports activities, as Table $\mathbf{5}$.

\subsection{Goal Programming Guiding Thought}

As the name suggests, goal programming is programming all given systematical problems by mathematical methods and further getting a group of optimal schemes of practice expected goal. Goal programming overcomes linear programming constraints that only solve a 
Table 5. Goal programming data investigation table.

\begin{tabular}{|c|c|c|c|c|c|}
\hline Course Content & Square Dance & Taijiquan & Martial Arts & Badminton & Sports Dance \\
\hline \hline Participants amount percentage\% & 12.8 & 13.1 & 12.7 & 10.4 & 9.6 \\
\hline Average participation time/h & 3.5 & 4.0 & 2.1 & 3.0 & 2.1 \\
\hline Happiness index after exercising & 8.5 & 9.0 & 7.4 & 5.3 & 6.8 \\
\hline
\end{tabular}

group of linear constraint conditions. In addition, in real life, to certain goals, they should have primary and secondary ones, and also mutual complementation and mutual antagonism. Meanwhile, there is also maximum value, minimum value as well as a difference of quantitative and qualitative, LP cannot solve these problems, while goal programming just overcomes the drawback.

Generally, goal programming has three kinds of methods, weighted coefficient method, priority method and effective solution method. Among them, weighted coefficient method is defining a weight on every solved goal, and further converting complicated multiple goals problems into single goal problems, but its weight rationality is hard to set; priority method is to classify each goal into different grades, its classification evidence is each goal importance. Effective solution can take all goals into account and further get most satisfied solution.

Goal programming objective function is composed according to each goal constraints positive and negative deviation quantities and assigned corresponding priority factors. Its general basic form is :

Try to make positive and negative deviation small, and then further just arrive at goal value: $\min z=f\left(d^{+}+d^{-}\right)$

Try to make positive deviation small, no need to arrive at goal value: $\min z=f\left(d^{+}\right)$

Try to make negative deviation small, surpass goal value and surpass quantity is not limited: $\min z=f\left(d^{-}\right)$

Among them, positive and negative deviation variables definitions are as following:

Known that $d$ is decision variable function, positive deviation variable $d^{+}=\max \left\{d-d_{0}, 0\right\}$ represents the part that calculation value surpasses goal regulated value, negative deviation variable $d^{-}=-\min \left\{d-d_{0}, 0\right\}$ represents the part that calculation value less than goal regulated value, and $d_{0}$ is $d$ goal regulated value, it always has $d^{+} \times d^{-}=0$.

Priority factor: $P_{1}, P_{2}, \cdots$, and it has $P_{k} \gg>P_{k+1}$, $k=1,1, \cdots, q$, which represents $P_{k}$ has bigger priority than $P_{k+1}$.

Goal programming normal mathematical model:

Known that $x_{j}(j=1,2, \cdots, n)$ is goal programming decision variable, it totally has $m$ pieces of constraints, and $l$ pieces of weak goal constraints, its goal programming constraint deviation is $d^{+}, d_{i}^{-}(i=1,2, \cdots, l)$. Set it has $q$ pieces of priorities that are respectively $P_{1}, P_{2}, P_{3}, \cdots, P_{q}$. In the same priority $P_{k}$, weights are different that are respectively $\omega_{k j}^{+}, \quad \omega_{k j}^{-}(j=1,2, \cdots, l)$. Therefore goal programming general mathematical expression is:

$$
\begin{aligned}
& \min z=\sum_{k=1}^{q} P_{k}\left(\sum_{j=1}^{l} \omega_{k j}^{-} d_{j}^{-}+\omega_{k j}^{+} d_{j}^{+}\right) \\
& \left\{\begin{array}{l}
\sum_{j=1}^{n} a_{i j} x_{j} \leq(=, \geq) b_{i}, i=1, \cdots, m \\
\sum_{j=1}^{n} c_{i j} x_{j}+d_{i}^{-}-d_{i}^{+}=g_{i}, i=1, \cdots, l \\
x_{j} \geq 0, j=1,2, \cdots, n \\
d_{i}^{-}, d_{i}^{+} \geq 0, i=1,2, \cdots, l
\end{array}\right.
\end{aligned}
$$

\subsection{Goal Programming Data Processing}

According to above goal programming guiding thought, carry out data processing with data of different exercises habits impacts status on mental health, here adopts sequential algorithm here. Sequential algorithm is according to priority order, decomposing complicated multiple goal programming problems, transforming into multiple simple goal programming problems, its main process is as following:

To $k=1,2 \cdots, q$, solve

$\min z=\sum_{j=1}^{l} P_{k}\left(\sum_{j=1}^{l} \omega^{-}{ }_{k j} d_{j}^{-}+\omega^{+}{ }_{k j} d_{j}^{+}\right)$

$\sum_{j=1}^{n} a_{i j} x_{j} \leq(=, \geq) b_{i}, i=1, \cdots, m$

$\sum_{j=1}^{n} c_{i j} x_{j}+d_{i}^{-}-d_{i}^{+}=g_{i}, i=1, \cdots, l$

$\sum_{j=1}^{l}\left(\omega_{s j}^{-} d_{j}^{-}+\omega_{s j}^{+} d_{j}^{+}\right) \leq z_{s}^{*}, s=1,2, \cdots, k-1$

$x_{j} \geq 0, j=1,2, \cdots, n$

$d_{i}^{-}, d_{i}^{+} \geq 0, i=1,2, \cdots, l$

Among them, optimal value is $z_{k}^{*}$ 
At first, most important is old people happiness index in these sports activities, therefore his priority lists the first grade $P_{1}$; secondly, old people happiness index suffers physical exercise time influences, is the second grade $P_{2}$; finally, physical exercise environment is also factor that affects old people happiness index, is the third grade $P_{3}$. It is required old people happiness index should be larger than 7.0. Therefore, it gets corresponding goal programming model :

$$
\begin{aligned}
& \min z=P_{1} d_{1}^{-}+P_{2}\left(d_{2}^{+}+d_{2}^{-}\right)+P_{3}\left(3 d_{3}^{+}+3 d_{3}^{-}+d_{4}^{+}\right) \\
& 12.8 x_{1}+13.1 x_{2}+12.7 x_{3}+10.4 x_{4}+9.6 x_{5}=100 \\
& 3.5 x_{1}+4.0 x_{2}+2.1 x_{3}+3.0 x_{4}+2.1 x_{5} \geq 3.0 \\
& 8.5 x_{1}+9.0 x_{2}+7.4 x_{3}+5.3 x_{4}+6.8 x_{5} \geq 7.0 \\
& x_{1}, x_{2}, \cdots, x_{i}, d_{i}^{+}, d_{i}^{-} \geq 0, i=1,2, \cdots, 5
\end{aligned}
$$

Calculate above objective function by MATLAB software, and further get goal programming optimal solution is : $z^{*}=(1,2,3)$, and old people happiness index is 8.2.

\subsection{Result Analysis}

From above goal programming solution, it is clear that after physical exercise, old people happiness index is obviously higher, from which Taijiquan, square dance, martial arts these three kinds of physical exercises have largest impacts on old people happiness index, their happiness indexes are higher by comparing to other kinds of physical exercises. Therefore, in the aspect of promoting old people old year living quality, subjective well-being, take more physical exercises, especially for taijiquan, square dance, martial arts and other self-cultivation sports activities that have great effects on promoting old people happiness and avoiding mental diseases occurrence.

\section{CONCLUSION}

The paper carries out comprehensive analysis and comparative analysis of Chinese old people physical exercises basic status and old people physical health status, by researching on physical exercises participation old people age structure, average daily exercise time, curative effects on common aged-diseases and so on, it analyzes and gets that old people physical exercises age group concentrates on $50 \sim 80$ years old, and 55 75 years old are in the majority, average daily exercise time is basically above 3 hours, affected by physical exercises, incidence rate of Senile dementia, depression, hypertension, coronary heart disease obviously reduce.

The paper bases on old people physical exercise status analysis, apply mathematics grey correlation degree method and goal programming method, make quantitative analysis of square dance, Taijiquan, martial arts, badminton, sports dance, aerobics, swimming, shuttlecock and other sports activities old people satisfaction indexes, and targeted at the result, it further carries out goal programming research, establishes old people highest happiness index optimization model, and then gets conclusions: square dance, Taijiquan, martial arts, badminton, sports dance are several kinds of sports activities of higher old people satisfaction index, from which Taijiquan, square dance, martial arts have largest impacts on old people happiness index, they are one of paths that should be considered in future promoting old people life happiness.

\section{CONFLICT OF INTEREST}

The author confirms that this article content has no conflict of interest.

\section{ACKNOWLEDGEMENTS}

Declared none.

\section{REFERENCES}

[1] L. Jian-qiang, "Comparative research on difference between body shape and function and physical fitness of college students for different body-mass index level," J. Pla Inst. Phys. Educ., vol. 30, no.1, pp. 125-128, 2011

[2] L. Yin, and H. Cai-hua, "Influence of sports self-concept and selfefficacy on sports practice of university students," J. Sport. Adul Edu., vol. 27, no. 6, pp. 32-35, 2011.

[3] L. Hao, L. Lei, L. Li-ping, L. Xiao-mei, and Y. Ling-wei, "The analysis and research of the comprehensive intervention measures on over-weight or obesity middle-aged groups in hebei province," J. Hebei. Inst. Phys. Educ., vol. 22, no. 6, pp. 69-72, 2008.

[4] N. Jian-li, "Study of Transformation of College Students' Exercise Methods,” Bull. Sport. Sci. Technol., vol. 21, no. 4, pp. 85-87, 90, 2013.

[5] S. Dongzhe, and Y. Guang, "Study on physical characteristics and influencing factors of fat students with difference physical exercise," J. Hubei. Sport. Sci., vol. 32, no. 3, pp. 215-217, 2013.

[6] Y. Qiu-bo, and X. Hai-xiao, "Research on the differences of spare time exercise behavior between two different body weight students," Zhejiang Sport. Sci., vol. 35, no. 5, pp. 78-80, 2013. 